\title{
Thoracic epidural analgesia reduces myocardial injury in ischemic patients undergoing major abdominal cancer surgery
}

This article was published in the following Dove Press journal:

Journal of Pain Research

12 April 2017

Number of times this article has been viewed

\section{Mohamad Farouk \\ Mohamad' \\ Montaser A Mohammad' \\ Diab F Hetta' \\ Eman Hasan Ahmed ${ }^{2}$ \\ Ahmed A Obiedallah ${ }^{3}$ \\ Alaa Ali M Elzohry'}

'Department of Anesthesia, ICU and Pain Relief, ${ }^{2}$ Department of Clinical Pathology, South Egypt Cancer Institute, ${ }^{3}$ Department of Internal Medicine, Faculty of Medicine, Assiut University, Arab Republic of Egypt
Correspondence: Mohamad Farouk Mohamad

Assuit University, South Egypt

Cancer Institute, Anesthesia and Pain Management Department, 7I5I5,

El-Methaque street, Assuit city, Arab Republic of Egypt

Tel +20 88 2357007; +20 237484536

Fax +2088 2354I30; +20 237487704

Email mfaroukma@gmail.com
Background and objectives: Major abdominal cancer surgeries are associated with significant perioperative mortality and morbidity due to myocardial ischemia and infarction. This study examined the effect of perioperative patient controlled epidural analgesia (PCEA) on occurrence of ischemic cardiac injury in ischemic patients undergoing major abdominal cancer surgery.

Patients and methods: One hundred and twenty patients (American Society of Anesthesiologists grade II and III) of either sex were scheduled for elective upper gastrointestinal cancer surgeries. Patients were allocated randomly into two groups (60 patients each) to receive, besides general anesthesia: continuous intra and postoperative intravenous (IV) infusion with fentanyl for $72 \mathrm{~h}$ postoperatively (patient controlled intravenous analgesia [PCIA] group) or continuous intra and postoperative epidural infusion with bupivacaine $0.125 \%$ and fentanyl (PCEA group) for $72 \mathrm{~h}$ postoperatively. Perioperative hemodynamics were recorded. Postoperative pain was assessed over $72 \mathrm{~h}$ using visual analog scale (VAS). All patients were screened for occurrence of myocardial injury (MI) by electrocardiography, echocardiography, and cardiac troponin I serum level. Other postoperative complications as arrhythmia, deep venous thrombosis (DVT), pulmonary embolism, pneumonia, and death were recorded.

Results: There was a significant reduction in overall adverse cardiac events (myocardial injury, arrhythmias, angina, heart failure and nonfatal cardiac arrest) in PCEA group in comparison to PCIA group. Also, there was a significant reduction in dynamic VAS pain score in group PCEA in comparison to PCIA at all measured time points. Regarding perioperative hemodynamics, there was a significant reduction in intra-operative mean arterial pressure (MAP); and heart rate in PCEA group in comparison to PCIA group at most of measured time points while there was not a significant reduction in postoperative MAP and heart rate in the second and third postoperative days. The incidence of other postoperative complications such as DVT, pneumonia and in hospital mortality were decreased in PCEA group.

Conclusion: Perioperative thoracic epidural analgesia in patients suffering from coronary artery disease subjected to major abdominal cancer surgery reduced significantly postoperative major adverse cardiac events with better pain control in comparison with perioperative IV analgesia. Keywords: postoperative myocardial infarction, thoracic epidural analgesia, PCA

\section{Introduction}

Life expectancy has extended worldwide and a growing number of patients with multiple comorbidities including ischemic heart diseases and cancer have undergone surgeries. Consequently, postoperative cardiovascular complications are expected to increase, ${ }^{1}$ and perioperative acute myocardial infarction (AMI) has become a major health concern. ${ }^{2,3}$ 
It is well known that surgery induces a stress response, its extent is directly dependent on the magnitude of tissue destruction, and may be modified by the type of perioperative analgesia used. This stress response can lead to an increase in heart rate (HR) and blood pressure, which can precipitate episodes of myocardial ischemia. ${ }^{4}$

Perioperative myocardial infarction (PMI) is one of the most important predictors of short- and long-term morbidity and mortality associated with noncardiac surgery. ${ }^{5-8}$ Prevention of PMI is thus a prerequisite for the improvement in overall postoperative outcome.

Thoracic epidural anesthesia (TEA) has been established as a cornerstone in perioperative care after thoracic and major abdominal surgery providing most effective analgesia. ${ }^{9,10}$ Beyond its analgesic properties, TEA's effects on postoperative neurohumoral stress response, cardiovascular pathophysiology, and intestinal dysfunction have been in the focus of both clinical and experimental investigations for years. ${ }^{11-15}$

The aim of the study was to test whether epidural analgesia added to a general anesthetic, compared with systemic, opioid-based standard care analgesia in ischemic patients undergoing major abdominal cancer surgery, provided any reduction in adverse cardiac events.

\section{Patients and methods}

This study was approved by the local ethics committee of the South Egypt Cancer Institute, Assiut University, Assiut, Egypt. After obtaining written informed consent from each patient, 120 adult patients, complaining of coronary artery disease (CAD), classified as American Society of Anesthesiologists grade II and III and New York Heart Association class II and III, scheduled for elective major abdominal cancer surgery were consecutively enrolled.

Patients with coagulopathy, active neurological disease, cutaneous disorders at the epidural insertion site, and allergy to the studied medications were excluded from the study.

Every patient was evaluated by a cardiologist and anesthesiologist for medical history, physical examination, electrocardiography (ECG), and echocardiography.

Anti-ischemic and antihypertensive drugs were continued during the perioperative period, including the morning of surgery; however, angiotensin-converting enzyme inhibitors, diuretics, and calcium channel blockers were suspended the day before surgery.

The day before surgery, all patients were taught how to evaluate their own pain intensity using the visual analog scale (VAS), scored from 0 to 10 (where $0=$ no pain and
$10=$ worst pain imaginable) and how to use the patient controlled analgesia (PCA) device (Abbott Laboratories, North Chicago, IL, USA).

Each patient was given oral ranitidine tablet, $50 \mathrm{mg}$ and lorazepam tablet, $3 \mathrm{mg}$ on the night of surgery. Patients were randomly assigned into two groups, 60 patients each, by using opaque sealed envelopes containing a computer generated randomization schedule; the opaque envelopes were sequentially numbered and were opened before application of anesthetic plan.

In the patient controlled intravenous analgesia (PCIA) group $(\mathrm{N}=60)$, patients received intraoperative analgesia with intravenous fentanyl bolus dose, $0.5 \mu \mathrm{g} / \mathrm{kg}$, followed by continuous infusion of $1 \mu \mathrm{g} / \mathrm{kg} / \mathrm{h}$ till the end of surgery. Postoperative analgesia consisted of intravenous fentanyl PCA, $10 \mu \mathrm{g} / \mathrm{mL}$, background infusion $2 \mathrm{~mL} / \mathrm{h}$, bolus dose $3 \mathrm{~mL}$ and lockout interval $15 \mathrm{~min}$.

In the patient controlled epidural analgesia (PCEA) group $(\mathrm{N}=60)$, where patients received PCEA in conjunction with GA, intraoperative analgesia was started before skin incision by epidural bolus dose of $0.1 \mathrm{~mL} / \mathrm{kg}$ of $0.125 \%$ bupivacaine/ fentanyl $10 \mu \mathrm{g} / \mathrm{mL}$, followed by continuous infusion of $0.1 \mathrm{~mL} / \mathrm{kg} / \mathrm{h}$ of $0.125 \%$ bupivacaine/fentanyl $5 \mu \mathrm{g} / \mathrm{mL}$ until the end of surgery. Postoperative analgesia was provided through PCEA for $72 \mathrm{~h}$ postoperatively (background infusion of $0.1 \mathrm{~mL} / \mathrm{kg} / \mathrm{h}$ of $0.125 \%$ bupivacaine/fentanyl $3 \mu \mathrm{g} /$ $\mathrm{mL}$, bolus dose of $3 \mathrm{~mL}$, lockout interval was set at $20 \mathrm{~min}$ ).

\section{The technique of thoracic epidural}

Before induction of GA and under strict aseptic precautions, thoracic epidural catheter was inserted using a 16 gauge, Tuohy epidural needle by a paramedian approach. T8-T9 interspace was chosen for the injection. Skin at insertion site was anesthetized by $3 \mathrm{~mL}$ of lidocaine $1 \%$, the epidural space was identified by the loss of resistance technique, the catheter was introduced $\sim 2-4 \mathrm{~cm}$ into the epidural space, and epidural test dose of $3 \mathrm{~mL}$ of lidocaine $2 \%$ with 1:200,000 adrenaline was injected to confirm its position. The epidural was loaded with $0.1 \mathrm{~mL} / \mathrm{kg}$ of $0.125 \%$ bupivacaine/fentanyl $10 \mu \mathrm{g} / \mathrm{mL}$ to obtain T4 sensory level; if the injected dose was not enough to achieve $\mathrm{T} 4$, another dose of $0.05 \mathrm{~mL} / \mathrm{kg}$ was injected.

\section{GA}

After preoxygenation for $3 \mathrm{~min}$, anesthesia was induced with IV propofol $(1.5 \mathrm{mg} / \mathrm{kg})$ and fentanyl $2 \mu \mathrm{g} / \mathrm{kg}$. Tracheal intubation was performed after adequate neuromuscular blockade with cisatracurium $0.15 \mathrm{mg} / \mathrm{kg}$. Anesthesia was 
maintained by isoflurane 1-1.5 minimum alveolar concentration (MAC); cisatracurium $0.03 \mathrm{mg} / \mathrm{kg}$ was administered when indicated. Fentanyl $0.5 \mu \mathrm{g} / \mathrm{kg}$ was given to maintain HR and blood pressure within $20 \%$ of the basal value. Patients were mechanically ventilated to maintain end tidal $\mathrm{CO}_{2}$ between 35 and $40 \mathrm{mmHg}$. The inspired oxygen fraction $\left(\mathrm{FIO}_{2}\right)$ was 0.5 using oxygen-and-air mixtures. At the end of surgery, neuromuscular block was antagonized in all patients with neostigmine $0.05 \mathrm{mg} / \mathrm{kg}$ and atropine $0.02 \mathrm{mg} /$ $\mathrm{kg}$ and finally the patients were extubated in the operating room. Hypotension was determined as systolic blood pressure $<85 \mathrm{mmHg}$ and was managed with IV ephedrine $0.1 \mathrm{mg} / \mathrm{kg}$. Bradycardia was determined as HR slower than 50 beats $/ \mathrm{min}$ and was taken care of by atropine $0.01 \mathrm{mg} / \mathrm{kg}$.

All patients were admitted to the surgical intensive care unit (ICU), and were followed up for 2 weeks by the following observations:

1. 12-lead ECG was recorded daily and if there was any suspicion of ischemic attacks.

2. Vital signs were recorded every $1 \mathrm{~h}$ in the ICU.

3. Echocardiography was requested if there ECG findings (on continuous monitoring) suggested ischemic episodes or if the patient's complaint was consistent with angina. (All ECGs and echocardiography were analyzed by a consultant cardiologist who was blinded to the patients' condition.)

4. VAS was recorded every $4 \mathrm{~h}$ for 3 days postoperatively.

5. Venous blood samples for troponin I measurement were withdrawn routinely every day and at any time if there were ECG findings suggestive of ischemia.

The primary endpoint was the overall occurrence of adverse cardiac events that include

1. new ECG findings suggestive of ischemia such as new ST segment changes, new pathologic Q wave, or new $\mathrm{T}$ wave inversion;

2. new echocardiographic findings suggestive of ischemia (new regional wall motion abnormalities);

3. new critical arrhythmia, such as atrial flutter and fibrillation, second or third degree heart block, and any other arrhythmia affecting the hemodynamics;

4. postoperative myocardial infarction diagnosed clinically, and by ECG and echocardiography, and in conjunction with cardiac troponin I, level $>0.23 \mathrm{ng} / \mathrm{mL}$ was considered the cut-point for diagnosis of myocardial injury (MI);

5. nonfatal cardiac arrest;

6. heart failure, diagnosed clinically (new in-hospital signs or symptoms of dyspnea, orthopnea, paroxysmal nocturnal dyspnea, increased jugular venous pressure, pulmonary rales on physical examination) and by measuring B-type natriuretic peptide (BNP) level (the decision cut-point of BNP level for the diagnosis of heart failure was identical to that of $100 \mathrm{pg} / \mathrm{mL}){ }^{16}$

The secondary endpoints were

1. intensity of pain measured by VAS (resting and dynamic);

2. occurrence of other systems adverse events and complications;

3. all in-hospital 30 days mortality.

\section{Technique of measurement}

Blood samples for troponins I and plasma BNP levels were collected in non-pyrogenic, sterile falcon tubes. Troponin I and BNP were measured by a newly developed high-sensitive Elecsys analyzer (fully automated enzyme linked immunosorbent assay [ELISA] EVOLIS; Bio-Rad Laboratories Inc., Hercules, CA, USA). BNP kit uses competitive ELISA as the method while the cardiac-specific troponin I (cTnI) ELISA test is based on the principle of a solid phase ELISA.

\section{Statistical analysis}

Statistical analysis was carried out on a personal computer using Statistical Package for the Social Sciences (SPSS) version 20 software. The sample size included all eligible patients admitted to the institute from August 2014 to August 2016 who were consecutively enrolled. Normality of continuous data distribution was tested using the KolmogorovSmirnov test. Normally distributed continuous data were described as mean and standard deviation. Independent samples Student's $t$-test was used for comparison between two independent groups (PCIA and PCEA). Skewed data were presented as median (interquartile range) and differences between the two groups were compared nonparametrically using Mann-Whitney $U$ test. $P<0.05$ was considered statistically significant.

\section{Results}

The flow of the patients through the study is illustrated in Figure 1. The demographic data and the characteristics of the patients were similar between groups (Table 1). There was a significant decrease in overall adverse cardiac events (myocardial injury, ventricular and atrial arrhythmia, angina, heart failure and nonfatal cardiac arrest) in PCEA group in comparison to PCIA group (Table 2). The level of troponin I was significantly higher in group PCEA in comparison to group PCIA at all measured time points $(P<0.038)$ (Figure 3 ). The number of patients with increased troponin 


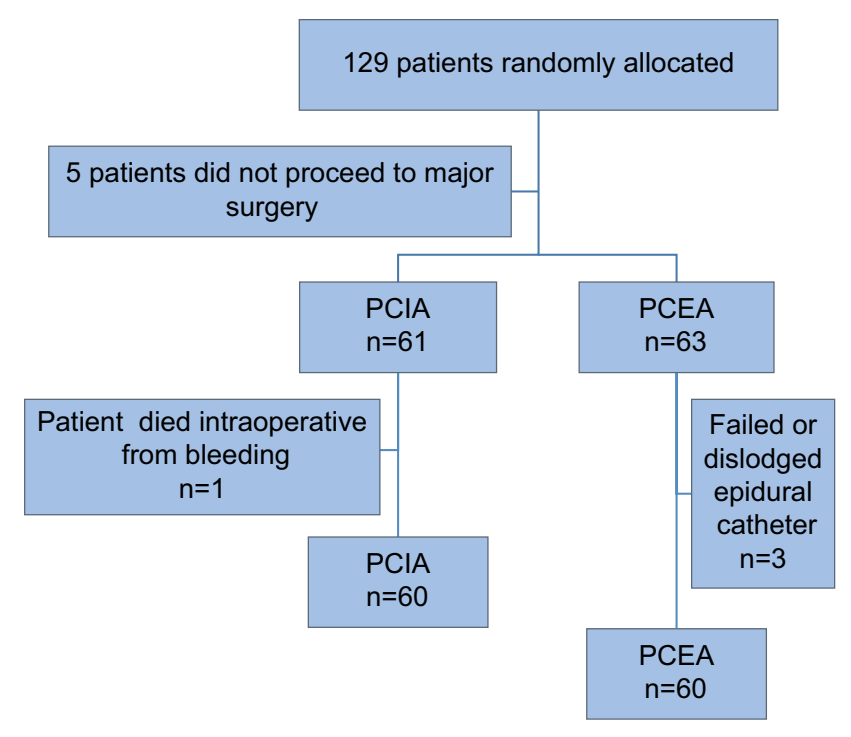

Figure I Flow diagram of patients.

Abbreviations: PCIA, patient controlled intravenous analgesia; PCEA, patient controlled epidural analgesia.

level was higher in PCIA group (Figure 4). Regarding post-operative pain, the VAS pain score at rest was similar between groups (Table 3), while the VAS pain score during movement was significantly decreased in PCEA group in comparison to PCIA group at all measured time points $(P<0.04)$ (Figure 2$)$. Regarding perioperative hemodynamics, there was a significant reduction in intra-operative MAP and heart rate in PCEA group in comparison to PCIA group at most of measured time points while there was no significant reduction in postoperative MAP and heart rate in the second and third post-operative days (Table 4). The incidence of other postoperative complications such as DVT, pneumonia and in hospital mortality were decreased in PCEA group (Table 2).

\section{Discussion}

The present study showed that perioperative thoracic epidural analgesia in patients suffering from CAD subjected to major abdominal cancer surgery reduced significantly postoperative major adverse cardiac events in comparison with perioperative IV analgesia (Table 2). Moreover, the intensity of pain during movement was significantly decreased in PCEA group in comparison to PCIA group.

The choice of $72 \mathrm{~h}$ as the period for PCA (either IV or epidural) because of the large proportion of clinically unrecognized AMI is related to the fact that most AMI occur during the early postoperative period. ${ }^{17}$

In agreement with the present study, previous study showed that cardiac morbidity was lower among patients undergoing major vascular surgery after the administration
Table I Demographic data and patients' characteristics

\begin{tabular}{|c|c|c|c|}
\hline Variables & $\begin{array}{l}\text { PCIA group } \\
(n=60)\end{array}$ & $\begin{array}{l}\text { PCEA group } \\
(n=60)\end{array}$ & $P$-value \\
\hline Age & $\begin{array}{l}63.73 \pm 5.61 \\
(55-74)\end{array}$ & $\begin{array}{l}61.73 \pm 6.07 \\
(55-74)\end{array}$ & 0.191 \\
\hline Gender, M/F & $29 / 31$ & $27 / 33$ & 0.592 \\
\hline $\mathrm{BMI}, \mathrm{kg} / \mathrm{m}^{2}$ & $22.1 \pm 3.3$ & $23.9 \pm 1.5$ & 0.066 \\
\hline \multicolumn{4}{|l|}{ ASA, n (\%) } \\
\hline II & $31(53.3)$ & $36(60.0)$ & 0.501 \\
\hline III & $29(46.7)$ & $24(40.0)$ & 0.501 \\
\hline Operative duration (hours) & $\begin{array}{l}5.64 \pm 0.7 \\
(4.4-7)\end{array}$ & $\begin{array}{l}5.4 I \pm 0.68 \\
(4.3-7)\end{array}$ & 0.196 \\
\hline \multicolumn{4}{|l|}{ Type of surgery } \\
\hline Gastrectomy & $33(56.7 \%)$ & $30(50.0 \%)$ & 0.795 \\
\hline Whipple's surgery & $13(23.3 \%)$ & $17(26.7 \%)$ & 0.998 \\
\hline Distal esophagectomy & $14(20.0 \%)$ & $13(23.3 \%)$ & 0.976 \\
\hline \multicolumn{4}{|l|}{ Other diseases } \\
\hline Hypertension & $30(50 \%)$ & $33(53.3 \%)$ & 0.798 \\
\hline DM & $32(53.3 \%)$ & $30(50 \%)$ & 0.798 \\
\hline Renal failure & $8(13.3 \%)$ & $10(16.7 \%)$ & 0.712 \\
\hline COPD & $4(6.7 \%)$ & $6(10 \%)$ & 0.644 \\
\hline Hyperlipidemia & $13(46.7 \%)$ & $24(40 \%)$ & 0.601 \\
\hline RCRI & $3.07 \pm 0.78(2-4)$ & $3.07 \pm 0.58(2-4)$ & 1.000 \\
\hline \multicolumn{4}{|l|}{ ECG finding except ischemia } \\
\hline $\mathrm{AF}$ & $20(33.3 \%)$ & $22(36.7 \%)$ & 0.782 \\
\hline PAE & $9(13.3 \%)$ & $9(13.3 \%)$ & 1.000 \\
\hline BBB & $9(13.3 \%)$ & $10(6.7 \%)$ & 0.394 \\
\hline Ventricular hypertrophy & $20(33.3 \%)$ & $21(33.3 \%)$ & 1.000 \\
\hline \multicolumn{4}{|c|}{ Site of ischemic changes on ECG } \\
\hline INF IHD & $28(46.7 \%)$ & $28(46.7 \%)$ & 1.000 \\
\hline ANT IHD & $4(6.7 \%)$ & I (I.8\%) & 0.374 \\
\hline Lat IHD & $16(26.7 \%)$ & $8(13.3 \%)$ & 0.194 \\
\hline Mixed IHD & $12(20 \%)$ & $24(40 \%)$ & 0.091 \\
\hline \multicolumn{4}{|l|}{ Treatment } \\
\hline Beta-blockers & $54(90 \%)$ & $57(93.3 \%)$ & 0.644 \\
\hline Nitrate & $18(30 \%)$ & $18(26.7 \%)$ & 0.777 \\
\hline Antiplatelets & $22(36.7 \%)$ & $25(43.3 \%)$ & 0.602 \\
\hline ACE inhibitor & $23(80 \%)$ & $26(76.7 \%)$ & 0.756 \\
\hline Diuretics & $18(30 \%)$ & $14(23.3 \%)$ & 0.557 \\
\hline \multicolumn{4}{|l|}{$\mathrm{ECHO}$ findings } \\
\hline SWMA & $18(30 \%)$ & $8(26.7 \%)$ & 0.777 \\
\hline Dilated atrium or ventricle & $28(46.7 \%)$ & $26(43.3 \%)$ & 0.791 \\
\hline Pulmonary hypertension & $9(15 \%)$ & $12(20 \%)$ & 0.582 \\
\hline Hypertrophic ventricle & $20(33.3 \%)$ & $16(24.2 \%)$ & 0.577 \\
\hline $\mathrm{EF}$, mean $\pm \mathrm{SD}$ (range) & $\begin{array}{l}49.8 \pm 5.99 \\
(41-60)\end{array}$ & $\begin{array}{l}49.4 \pm 5.52 \\
(39-59)\end{array}$ & 0.789 \\
\hline
\end{tabular}

Notes: Data were expressed as mean \pm SD. $P<0.05$ is considered statistically significant. Between the two groups, there were no significant differences regarding patient characteristics.

Abbreviations: PCIA, patient controlled intravenous analgesia; PCEA, patient controlled epidural analgesia; M/F, male/female; BMI, body mass index; ASA, American Society of Anesthesiologists; DM, diabetes mellitus; RCRI, revised cardiac risk index; ECG, electrocardiography; $A F$, atrial fibrillation; PAE, premature atrial ectopics; $B B B$, bundle branch block; ACE, angiotensin-converting enzyme; $E C H O$, echocardiogram; SWMA, segmental wall-motion abnormalities; SD, standard deviation; EF, ejection fraction; IHD: ischemic heart disease; Lat, lateral; INF; inferior; ANT, anterior; COPD, chronic obstructive pulmonary disease..

of GA combined with postoperative epidural analgesia compared to the administration of GA alone and postoperative systemic opioid analgesia. ${ }^{18}$ 
Table 2 Postoperative outcome

\begin{tabular}{llll}
\hline Outcome & PCIA (N=60) & PCEA (N=60) & P-value \\
\hline Myocardial injury & $22(36.67 \%)$ & $5(8.33 \%)$ & $0.00 \mathrm{I}$ \\
Ventricular arrhythmia & $14(23.33 \%)$ & $5(8.33 \%)$ & 0.042 \\
Atrial arrhythmia & $22(36.67 \%)$ & $7(11.66 \%)$ & 0.012 \\
Angina & $33(55 \%)$ & $10(16.66 \%)$ & $0.00 \mathrm{I}$ \\
Heart failure & $9(15 \%)$ & $4(6.67 \%)$ & 0.038 \\
Nonfatal cardiac arrest & $4(6.67 \%)$ & $2(3.33 \%)$ & 0.044 \\
Pulmonary embolism & $3(5 \%)$ & $\mathrm{I}(1.67 \%)$ & $0.00 \mathrm{I}$ \\
Pneumonia & $6(10 \%)$ & $\mathrm{I}(1.67 \%)$ & 0.000 \\
Deep venous thrombosis & $2(3.33 \%)$ & $0(0 \%)$ & $\mathrm{N} / \mathrm{A}$ \\
In hospital mortality & $2(3.33 \%)$ & $\mathrm{I}(\mathrm{I} .67 \%)$ & 0.896 \\
\hline
\end{tabular}

Notes: Data are expressed as numbers and percentages, $P<0.05$ is considered statistically significant.

Abbreviations: PCIA, patient controlled intravenous analgesia; PCEA, patient controlled epidural analgesia.

Table 3 Postoperative resting VAS

\begin{tabular}{|c|c|c|c|}
\hline \multirow[t]{2}{*}{ VAS } & \multicolumn{2}{|c|}{ Median (IQ range) } & \multirow[t]{2}{*}{$P$-value } \\
\hline & $\begin{array}{l}\text { PCIA group } \\
(n=60)\end{array}$ & $\begin{array}{l}\text { PCEA group } \\
(n=60)\end{array}$ & \\
\hline VAS O h & $3(2: 4)$ & $3(2: 3)$ & 0.127 \\
\hline VAS $4 \mathrm{~h}$ & $3(2: 4)$ & $2(2: 4)$ & 0.778 \\
\hline VAS $8 \mathrm{~h}$ & $3(2: 3)$ & $3(2: 3)$ & 0.472 \\
\hline VAS $12 \mathrm{~h}$ & $2(2: 3)$ & $2(2: 3)$ & 0.429 \\
\hline VAS $16 \mathrm{~h}$ & $2(2: 3)$ & $3(2: 3)$ & 0.121 \\
\hline VAS $20 \mathrm{~h}$ & $2(1: 3)$ & $3(2: 4)$ & 0.193 \\
\hline VAS $24 \mathrm{~h}$ & $2(2: 2)$ & $2(2: 3)$ & 0.055 \\
\hline VAS $28 \mathrm{~h}$ & $2(1: 3)$ & $2(2: 3)$ & 0.794 \\
\hline VAS $32 \mathrm{~h}$ & $2(2: 3)$ & $2(2: 3)$ & 0.180 \\
\hline VAS $36 \mathrm{~h}$ & $3(2: 3)$ & $3(2: 3)$ & 0.121 \\
\hline VAS $40 \mathrm{~h}$ & $2(2: 3)$ & $2.5(1: 3)$ & 0.307 \\
\hline VAS $44 \mathrm{~h}$ & $2.5(2: 3)$ & $2(2: 2.8)$ & 0.091 \\
\hline VAS $48 \mathrm{~h}$ & $3(2: 3)$ & $2(2: 3)$ & 0.113 \\
\hline VAS $52 \mathrm{~h}$ & $2(1: 3)$ & $3(2: 3)$ & 0.194 \\
\hline VAS $56 \mathrm{~h}$ & $2(2: 2)$ & $2(2: 3)$ & 0.057 \\
\hline VAS $60 \mathrm{~h}$ & $2.5(2: 3)$ & $2(2: 2.8)$ & 0.091 \\
\hline VAS $64 \mathrm{~h}$ & $3(2: 3)$ & $2(2: 3)$ & 0.113 \\
\hline VAS $68 \mathrm{~h}$ & $2(1: 3)$ & $3(2: 3)$ & 0.194 \\
\hline VAS $72 \mathrm{~h}$ & $2(2: 2)$ & $2(2: 3)$ & 0.057 \\
\hline
\end{tabular}

Notes: Data are expressed as IQ range. $P<0.05$ is considered statistically significant. Abbreviations: VAS, visual analog scale; PCIA, patient controlled intravenous analgesia; PCEA, patient controlled epidural analgesia; $h$, hour interval; $0 \mathrm{~h}$, reading at recovery; IQ, interquartile.

MASTER Trial showed a significant reduction in PMI with thoracic epidural catheters in comparison with control groups among 11 randomized studies involving 1,173 patients. Their inclusion criteria demanded that epidural analgesia should continue for at least $24 \mathrm{~h}$ after surgery, but their article does not state how they accounted for mortality among those patients randomized to the epidural group who may have died within the first $24 \mathrm{~h}^{19}$

The Cochrane study in 2016 concluded from a review of 15 clinical trials that epidural analgesia provides better pain management than systemic opioids. It significantly reduces the number of people who suffer heart damage, time to return of unassisted respiration, gastrointestinal bleeding, and ICU length of stay. No difference was found in death rates at 30 days. ${ }^{20}$

A study was conducted by Mohamed et al in the same institute to observe 60 ischemic patients, assigned into two groups, who underwent elective major abdominal cancer surgery; 30 patients receiving GA (G1) and the others receiving combined general and epidural anesthesia (G2). They concluded that lumbar epidural anesthesia combined with general anesthesia in high-risk patients with ischemic heart disease undergoing major abdominal cancer surgery provided better pain relief, and ischemic cardiac events were similar in both groups. ${ }^{22}$

According to Moltner, dysrhythmias are common complications in the immediate postoperative period, even more common after upper abdominal and thoracic surgeries. ${ }^{22}$

Scott et al presented the first randomized evaluation of the impact of perioperative TEA on outcome in a large series of 400 patients with normal ventricular function undergoing coronary artery bypass grafting, wherein epidural catheters were placed immediately before surgery. There was a reduction in the incidence of supraventricular arrhythmias. ${ }^{23}$

In agreement with the present analysis, a study conducted by Giroban et al registered dysrhythmias in the postoperative period of $20 \%$ of 185 patients undergoing thoracoabdominal surgeries. $^{24}$

The occurrence of arrhythmias can be explained by many factors such as preexisting cardiac pathology, intraoperative events, and arrhythmia triggers. Autonomic imbalance after operation has been implicated as a possible trigger, and is thought to be characterized by increased sympathetic tone and lower vagal tone. ${ }^{25}$

In this study, PCEA resulted in a better optimization of HR and mean arterial pressure during the intra and postoperative period in comparison with the PCIA group. This result showed the advantage of TEA over IV PCA by means of decreased HR and improved coronary blood flow.

Consistent with these results, Kessler et al compared HR between patients who received GA together with TEA (group1) and those who received only GA (group2) during coronary artery bypass surgery performed on a beating heart and reported that the HR in group 1 was lower than preoperative values, during sternotomy and anastomosis compared to group 2. In that study, IV esmolol was administered in the group that received GA because of a high HR. ${ }^{26}$ 


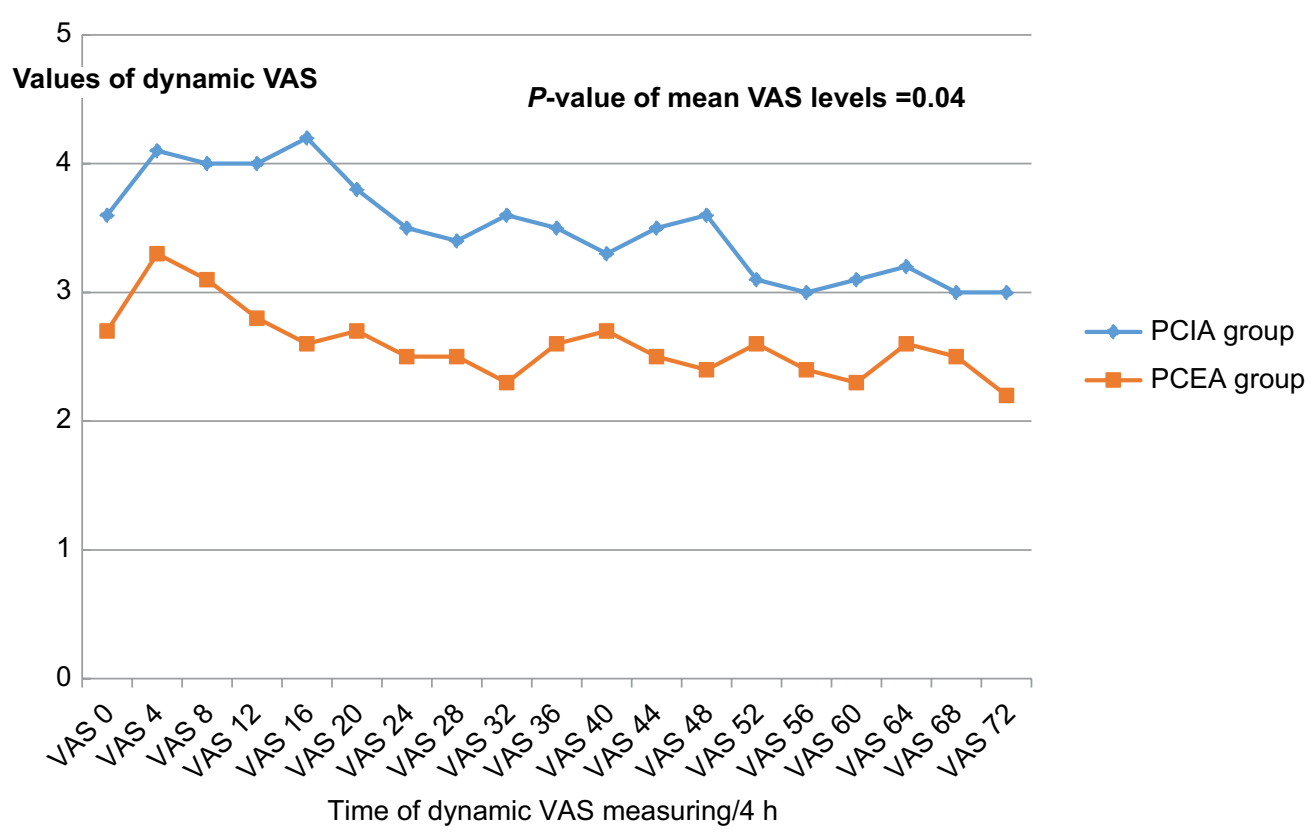

Figure 2 Dynamic VAS pain score between groups.

Note: $P<0.05$ is considered statistically significant.

Abbreviations: VAS, visual analog scale; PCIA, patient controlled intravenous analgesia; PCEA, patient controlled epidural analgesia; h, hour interval.

Table 4 Perioperative hemodynamics

\begin{tabular}{llll}
\hline Variable & PCIA (n=60) & PCEA (n=60) & P-value \\
\hline Basal MAP (mmHg) & $75.9 \pm 10.6$ & $80 \pm 9.3$ & 0.117 \\
Intra-op. MAP, I h & $82.47 \pm 10.4$ & $73.53 \pm 10.2$ & 0.013 \\
Intra-op. MAP, 2 h & $79.67 \pm 12.12$ & $65.07 \pm 7$ & 0.014 \\
Intra-op. MAP, 3 h & $75.73 \pm 11.79$ & $69.67 \pm 7.3$ & 0.025 \\
Intra-op. MAP, 4 h & $75.9 \pm 10$ & $80 \pm 9.3$ & 0.117 \\
Intra-op. MAP, end & $73.13 \pm 8.86$ & $72.93 \pm 4.95$ & 0.914 \\
Basal HR (bpm) & $72.8 \pm 11.0$ & $77.9 \pm 14.0$ & 0.126 \\
Intra-op. HR, I h & $85.13 \pm 10.37$ & $75.4 \pm 7.16$ & 0.012 \\
Intra-op. HR, 2 h & $82.93 \pm 18.02$ & $72.47 \pm 14.43$ & 0.016 \\
Intra-op. HR, 3 h & $82.27 \pm 13.96$ & $72.67 \pm 11.81$ & 0.016 \\
Intra-op. HR, 4 h & $80.07 \pm 14.14$ & $75.33 \pm 11.57$ & 0.161 \\
Intra-op. HR, end & $72.93 \pm 12.34$ & $72.73 \pm 13.05$ & 0.952 \\
Post-op. MAP, day, I & $77.21 \pm 4.63$ & $73.69 \pm 7.14$ & 0.031 \\
Post-op. MAP, day, 2 & $76.15 \pm 7.94$ & $73.75 \pm 7.96$ & 0.247 \\
Post-op. MAP, day, 3 & $72.37 \pm 9.72$ & $71.2 \pm 8.3$ & 0.617 \\
Post-op. HR, day, I & $96.91 \pm 21.78$ & $80.59 \pm 19.07$ & 0.003 \\
Post-op. HR, day, 2 & $88.53 \pm 15.14$ & $80.6 \pm 15.11$ & 0.047 \\
Post-op. HR, day, 3 & $85.11 \pm 11.9$ & $80.41 \pm 12.46$ & 0.148 \\
Post-op. CVP, day, I & $10.01 \pm 3.7$ & $8.89 \pm 2.72$ & 0.187 \\
Post-op. CVP, day, 2 & $9.76 \pm 3.89$ & $8.47 \pm 1.86$ & 0.106 \\
Post-op. CVP, day, 3 & $8.97 \pm 2.13$ & $8.13 \pm 1.59$ & 0.093 \\
\hline Note Dat
\end{tabular}

Notes: $D$ ata are presented as means $\pm S D$. $P<0.05$ was considered statistically significant. Abbreviations: $\mathrm{PCIA}$, patient controlled intravenous analgesia; PCEA, patient controlled epidural analgesia; intra.op, intraoperative; post.op, postoperative, MAP, mean arterial blood pressure; HR, heart rate; CVP, central venous pressure; basal, before induction of anesthesia; SD, standard deviation.

Berendes et al and Fillinger et al, however, reported contradictory results as they did not observe a difference in hemodynamic findings between the control group and the
TEA treatment group when they studied TEA in patients undergoing coronary artery bypass grafting. ${ }^{27,28}$

All the above studies resulted in low morbidity and mortality in patients receiving TEA and this reflected on hospital ICU stay. In contrast, the present study showed no significant difference with regard to ICU and hospital stay between the two groups. This is consistent with the observations of Kessler et al who found no differences in ICU and hospital stay between the TEA and GA groups. ${ }^{29}$

In contrast, Priestly et al found no difference in troponin levels between GA alone and GA plus high TEA groups. ${ }^{30}$

TEA modifies the electrical activity of the heart in addition to ventricular function and wall motion. Improvements in regional blood flow and reduction of major determinants of cardiac oxygen consumption lead to less severe ischemic injury. ${ }^{31}$

Large coronary epicardial arteries and coronary arterioles are densely innervated by sympathetic adrenergic nerve fibers. Cardiac sympathetic stimulation results in vasoconstriction of both normal and diseased coronary arteries in animals and in humans. ${ }^{32,33}$

In a canine model of experimentally induced cardiac ischemia, cardiac sympathectomy by TEA has been shown to increase regional cardiac blood flow, and redistribute coronary blood flow in favor of the endocardium in both normal and diseased areas..$^{31}$ Davis et al observed favorable alteration in myocardial oxygen supply demand ratio. ${ }^{34}$ 


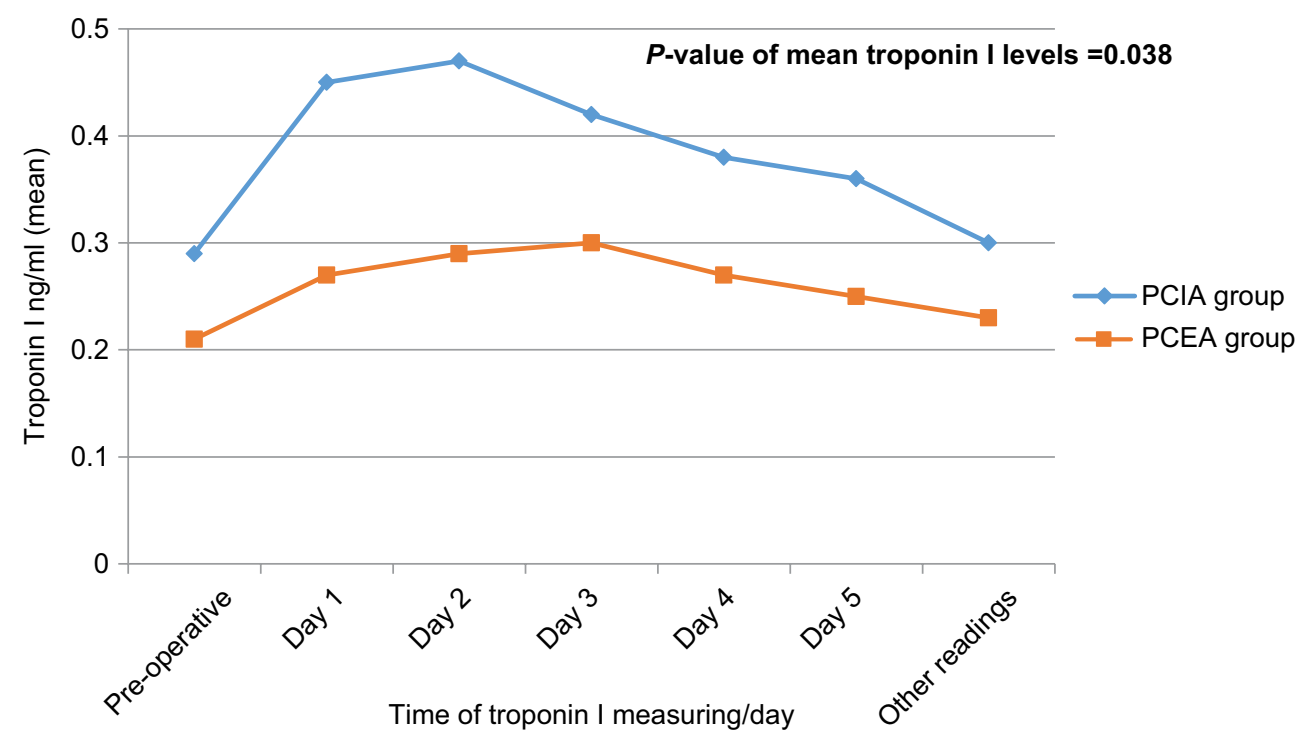

Figure 3 Values of troponin I.

Notes: Data are expressed as mean. $P<0.05$ is considered statistically significant.

Abbreviations: PCIA, patient controlled intravenous analgesia; PCEA, patient controlled epidural analgesia.

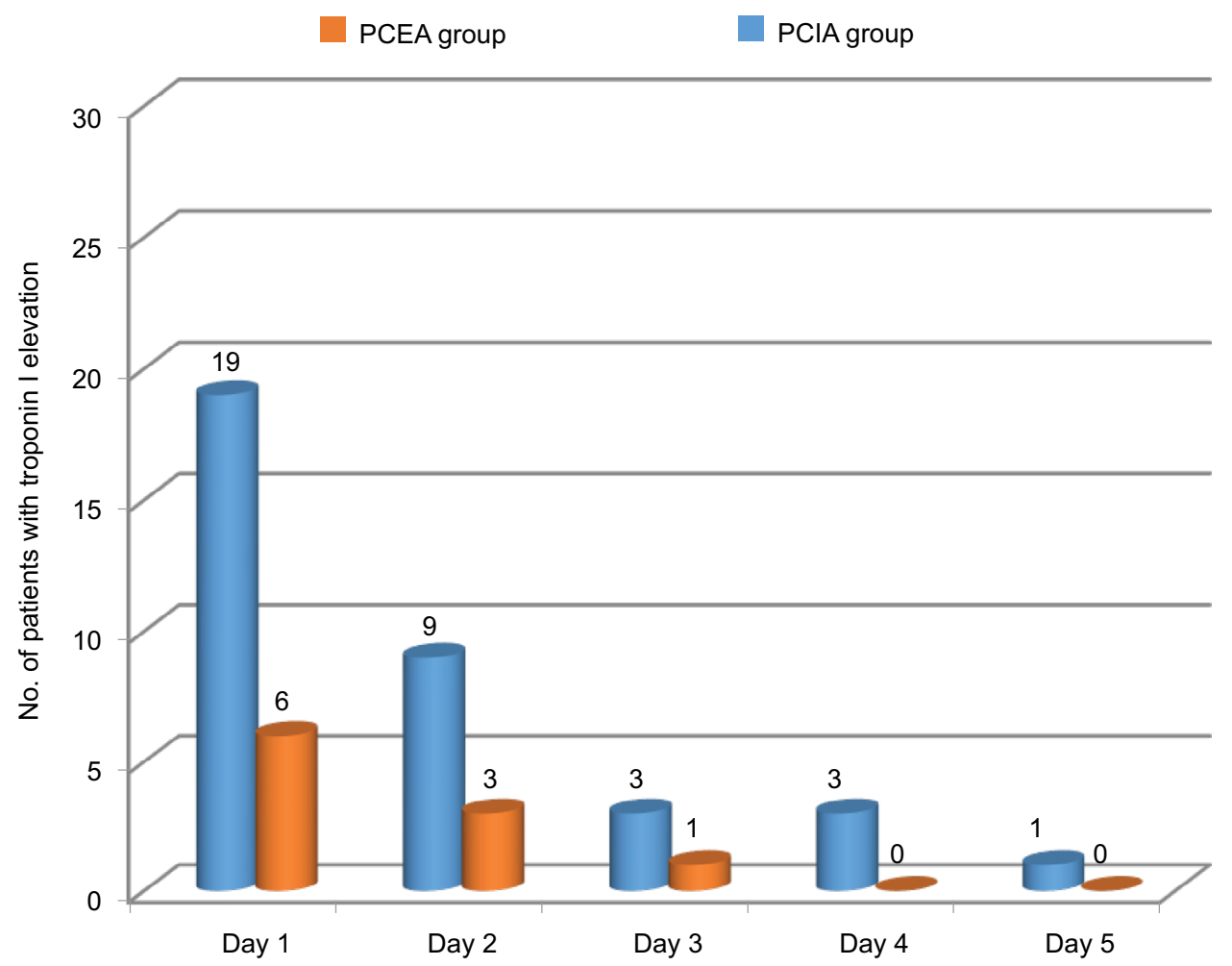

Figure 4 Number of patients with troponin I elevation in each group.

Abbreviations: PCEA, patient controlled epidural analgesia; PCIA, patient controlled intravenous analgesia.

In patients with severe $\mathrm{CAD}$, TEA relieved angina and improved myocardial oxygen supply by lowering systolic blood pressure and HR as well as pulmonary capillary wedge pressure with no significant improvement in coronary perfusion pressure..$^{35,36}$

Cardioselective epidural blocks can increase the luminal diameter of stenosed segments of epicardial coronary arteries without affecting the diameter of non-stenosed segments. ${ }^{37}$

\section{Study limitations}

Small sample size that may hinder providing well-drawn results with smaller statistical error and better conclusions with shorter duration follow-up period. 


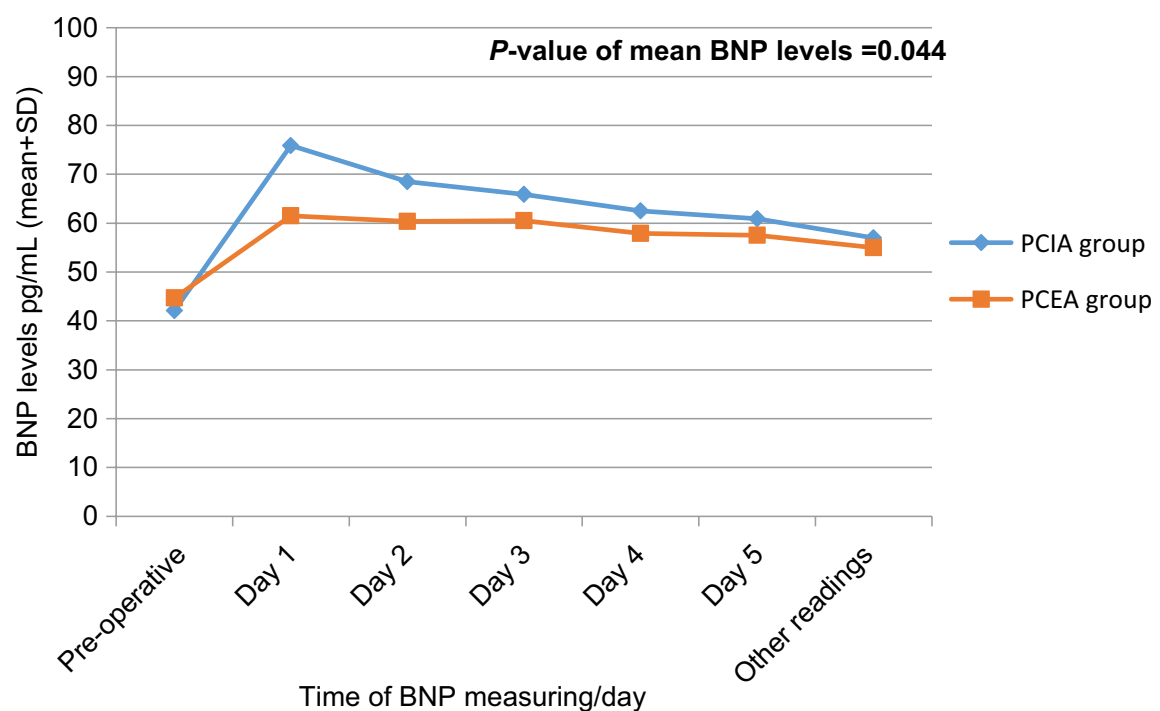

Figure 5 Values of BNP levels in each group.

Abbreviations: PCEA, patient controlled epidural analgesia; PCIA, patient controlled intravenous analgesia; BNP, B-type natriuretic peptide.

\section{Conclusion}

Perioperative thoracic epidural analgesia in patients suffering from CAD subjected to major abdominal cancer surgery reduced significantly postoperative major adverse cardiac events with better pain control in comparison with perioperative IV analgesia.

\section{Acknowledgment}

Funding was received from Assiut University, Arab Republic of Egypt.

\section{Disclosure}

All authors are lecturers in South Egypt Cancer Institute, Assiut University. The authors report no other conflicts of interest in this work.

\section{References}

1. Detsky AS, Abrams HB, Forbath N, Scott JG, Hilliard JR. Cardiac assessment for patients undergoing noncardiac surgery. A multifactorial clinical risk index. Arch Intern Med. 1986;146: 2131-2134.

2. Landesberg G, Beattie WS, Mosseri M, Jaffe AS, Alpert JS. Perioperative myocardial infarction. Circulation. 2009;119(22):2936-2944.

3. Adesanya AO, de Lemos JA, Greilich NB, Whitten CW. Management of perioperative myocardial infarction in noncardiac surgical patients. Chest. 2006;130(2):584-596.

4. Fleisher LA, Beckman J. Anesthesia and noncardiac surgery in patients with heart disease. In: Bonow RO, Mann D, Zipes D, Libby P, editors. Braunwald's Heart Disease - A Textbook of Cardiovascular Medicine. 9th ed. Philadelphia, PA: Saunders Elsevier; 2011: 1811-1828.

5. Landesberg G. The pathophysiology of perioperative myocardial infarction: facts and perspectives. J Cardiothorac Vasc Anesth. 2003; 17:90-100.

6. Mangano DT. Adverse outcomes after surgery in the year 2001 - a continuing odyssey (Editorial). Anesthesiology. 1998;88:561-564.

7. Mangano DT. Perioperative cardiac morbidity. Anesthesiology. 1990; $72: 153-184$.
8. Priebe HJ. Triggers of perioperative myocardial ischaemia and infarction. Br J Anaesth. 2004;93:9-20.

9. Popping DM, Zahn PK, Van Aken HK, Dasch B, Boche R, PogatzkiZahn EM. Effectiveness and safety of postoperative pain management: a survey of 18925 consecutive patients between 1998 and 2006 (2nd revision): a database analysis of prospectively raised data. Br JAnaesth. 2008; 101:832-840.

10. Royse C, Royse A, Soeding P, Blake D, Pang J. Prospective randomized trial of high thoracic epidural analgesia for coronary artery bypass surgery. Ann Thorac Surg. 2003;75:93-100.

11. Wu CL, Murphy JD. Epidural anesthesia - analgesia and patient outcomes: a perspective. Adv Anesthesiol. 2014;2014:5.

12. Liu SS. Anesthesia and analgesia for colon surgery. Reg Anesth Pain Med. 2004;29:52-57.

13. Kozian A, Schilling T, Hachenberg T. Non-analgetic effects of thoracic epidural anaesthesia. Curr Opin Anaesthesiol. 2005;18:29-34.

14. Liu SS, Wu CL. Effect of postoperative analgesia on major postoperative complications: a systematic update of the evidence. Anesth Analg. 2007;104:689-702.

15. Amini A, Patanwala AE, Maegawa FB, et al. Effect of epidural analgesia on postoperative complications following pancreaticoduodenectomy. Am J Surg, 2012;204(6):1000-1004; discussion 1004-1006.

16. Maisel AS, Koon J, Krishnaswamy P, et al. Utility of B-natriuretic peptide as a rapid, point-of-care test for screening patients undergoing echocardiography to determine left ventricular dysfunction. Am Heart J. 2001;141:367-374.

17. Mangano DT, Hollenberg M, Fegert G, et al. Perioperative myocardial ischemia in patients undergoing noncardiac surgery--I: incidence and severity during the 4 day perioperative period. The Study of Perioperative Ischemia (SPI) Research Group. J Am Coll Cardiol. 1991; 17(4):843-850.

18. Rodseth RN, Vasconcellos K, Naidoo P, et al. Preoperative B-type natriuretic peptide risk stratification: do postoperative indices add value? South Afr J Anaesth Analg. 2013;19(1):60-65.

19. Beattie W, Badner N, Choi P. Epidural analgesia reduces postoperative myocardial infarction: a meta-analysis. Anesth Analg. 2001;93:853-858.

20. Guay J, Kopp S. Epidural pain relief versus systemic opioid-based pain relief for abdominal aortic surgery. Cochrane Database Syst Rev. 2016;(1):CD005059.

21. Rodseth RN, LuratiBuse GA, Bolliger D, et al. The predictive ability of pre-operative B-type natriuretic peptide in vascular patients for major adverse cardiac events: an individual patient data meta-analysis. $J \mathrm{Am}$ Coll Cardiol. 2011;58:522-529. 
22. Mohamed SA, Fares KM, Hasan-Ali H, et al. The effect of anesthetic technique on cardiac troponin- $\mathrm{T}$ and systemic inflammatory response after major abdominal cancer surgery. JAnesth Clinic Res. 2013;4:296.

23. Moltner A, Holzl R, Strian F. Heart rate changes as an autonomic component of the pain response. Pain. 1990;43(1):81-89.

24. Scott DA, Beilby DS, McClymont C. Postoperative analgesia using epidural infusions of fentanyl with bupivacaine. A prospective analysis of 1,014 patients. Anesthesiology. 1995;83:727-737.

25. Giroban L, Dolinski SY, Zvara DA, et al. Thoracic epidural analgesia: its role in postthoracotomy atrial arrhythmias. J Cardoth Vasc Anest., 2000;14:662-665.

26. Kessler P, Aybek T, Neidhart G, et al. Comparison of three anesthetic techniques for off-pump coronary artery bypass grafting: general anesthesia, combined general and high thoracic epidural anesthesia, or high thoracic epidural anesthesia alone. J Cardoth Vasc Anest. 2005;19(1):32-39.

27. Berendes E, Schmidt C, van Aken H, et al. Reversible cardiac sympathectomy by high thoracic epidural anesthesia improves regional left ventricular function in patients undergoing coronary artery bypass grafting: a randomized trial. Arch Surg. 2003;138(12):1283-1290

28. Fillinger MP, Yeager MP, Dodds TM, Fillinger MF, Whalen PK, Glass DD. Epidural anesthesia and analgesia: effects on recovery from cardiac surgery. J Cardoth Vasc Anest. 2002;16(1):15-20.

29. Amar D, Zhang H, Miodownik S, et al. Competing autonomic mechanisms precede the onset of postoperative atrial fibrillation. $J$ Am Coll Cardiol. 2003;42:1262-1268.

30. Kessler P, Aybek T, Neidhart G, et al. Comparison of three anesthetic techniques for off-pump coronary artery bypass grafting: general anesthesia, combined general and high thoracic epidural anesthesia, or high thoracic epidural anesthesia alone. J Cardoth Vasc Anest. 2005;19(1):32-39.
31. Priestley MC, Cope L, Halliwell R, et al. Thoracic epidural anesthesia for cardiac surgery: the effects on tracheal intubation time and length of hospital stay. Anesth Analg. 2002;94:275-282, table of contents.

32. Blomberg S, Emanuelsson H, Kvist H, et al. Effects of thoracic epidural anesthesia on coronary arteries and arterioles in patients with coronary artery disease. Anesthesiology. 1990;73:840-847.

33. Berendes E, Schmidt C, Van Aken H, et al. Reversible cardiac sympathectomy by high thoracic epidural anesthesia improves regional left ventricular function in patients undergoing coronary artery bypass grafting: a randomized trial. Arch Surg. 2003;138:1283-1290; discussion 1291.

34. Klassen GA, Bramwell RS, Bromage PR, Zborowska-Sluis DT. Effect of acute sympathectomy by epidural anesthesia on the canine coronary circulation. Anesthesiology. 1980;52:8-15.

35. Blomberg S, Emanuelsson H, Ricksten SE. Thoracic epidural anesthesia and central hemodynamics in patients with unstable angina pectoris. Anesth Analg. 1989;69:558-562.

36. Davis RF, DeBoer LW, Maroko PR. Thoracic epidural anesthesia reduces myocardial infarct size after coronary artery occlusion in dogs. Anesth Analg. 1986;65:711-717.

37. Higham H, Sear JW, Sear YM, et al. Peri-operative troponin I concentration as a marker of long-term postoperative adverse cardiac outcomes - a study in high-risk surgical patients. Anaesthesia. 2004;59:318-323.

38. Saada M, Catoire P, Bonnet F, et al. Effect of thoracic epidural anesthesia combined with general anesthesia on segmental wall motion assessed by trans esophageal echocardiography. Anesth Analg. 1992;75:329-335.

39. Kock M, Blomberg S, Emanuelsson H, Lomsky M, Strömblad SO Ricksten SE. Thoracic epidural anesthesia improves global and regional left ventricular function during stress-induced myocardial ischemia in patients with coronary artery disease. Anesth Analg. 1990;71:625-630.
Journal of Pain Research

\section{Publish your work in this journal}

The Journal of Pain Research is an international, peer reviewed, open access, online journal that welcomes laboratory and clinical findings in the fields of pain research and the prevention and management of pain. Original research, reviews, symposium reports, hypothesis formation and commentaries are all considered for publication.

\section{Dovepress}

The manuscript management system is completely online and includes a very quick and fair peer-review system, which is all easy to use. Visit http://www.dovepress.com/testimonials.php to read real quotes from published authors. 